\title{
VANTAGENS ECONÔMICAS NAS TRANSAÇÕES COMERCIAIS NA INDÚSTRIA \\ OS CUSTOS RELEVANTES \\ E A GESTÃO ESTRATÉGICA DE CUSTOS
}

Valério Vitor Bonelli'

\section{RESUMO}

Face às exigências de mensuração, de informação e dos modelos de decisão, neste estudo discute-se Gestão Estratégica de Custos e os Custos Relevantes. Para e obtenção e a perenidade da vantagem competitiva, apresenta-se argumentos que corroboram a necessidade de discernimento entre a Gestão de Custos e Gestão Estratégica de Custos.

No atual jogo competitivo a Gestão Estratégica e a Gestão de Custos integradas, com destaque para os custos relevantes que serão abordados neste estudo, podem requerer um investimento em reorganização, que deve ser considerado à luz da relação custo-benefício para a empresa que pretende adotá-la, bem como, uma questão de atualização tecnológica com investimentos, que porém podem tornar-se irrelevantes dadas as possibilidades de se obter e manter capacidades diferenciadoras para a sustentação das vantagens competitivas e econômicas que suportam as estratégias de eficiência e eficácia nas transaçóes comerciais.

Palavras-chave: Gestão de Custos, Gestão Estratégica, Custos Relevantes, Vantagem Competitiva.

Professor da Pontifícia Universidade Católica de São Paulo. 


\section{INTRODUÇÃO}

O crescimento expressivo da competitividade que ocorre no ambiente econômico, faz com que se tornem altamente relevantes na tomada de decisão das organizações as informações sobre custos. A acirrada concorrência existente impossibilita que as empresas definam seus preços apenas de acordo com os gastos internos incorridos, logo é necessário observar os preços praticados no mercado.

O principal desafio enfrentado pela indústria principalmente atualmente é o aumento da produção com qualidade e a excelência nos serviços prestados, a um custo cada vez menor.

Procura-se discutir neste trabalho o tema sobre os custos relevantes e a Gestão Estratégica de Custos no contexto das empresas, principalmente industrial, no que tange a operacionalização, registros das transações, eventos, atividades, processos, áreas de decisão e mensuração de desempenho de empresas.

A existência de um desafio de alcançar esses objetivos em um ambiente econômico concorrencial e com produtos que apresentam diminuição do ciclo de vida, podem dificultar qualquer garantia de sustentabilidade. Para assegurarem a melhoria do desempenho organizacional, diante dessas demandas, existe a necessidade do uso de ferramentas gerenciais. Nesse contexto, destaca-se a Gestão Estratégica de Custos (GEC) que objetiva o alinhamento da estrutura de custos da organização com a sua estratégia (KAPLAN; ANDERSON, 2007).

Os sistemas de gestão de custos devem oferecer possibilidades de revelar o alinhamento das estratégias formuladas e projetadas pela alta cúpula das empresas, tornadas reais pelo direcionamento tático e executáveis pela supervisão operacional. Para este propósito os custos relevantes devem ser definidos e planificados a fim de serem identificados, adequadamente analisados e sistematizados, e usados como um diferencial competitivo.

O propósito deste estudo, portanto, é apresentar uma discussão e uma reflexão sobre a importância que se deve dar aos custos relevantes no atual ambiente e o uso destas informações de forma estratégica atuando e obtendo vantagem competitiva.

Esse estudo se caracteriza também como um ensaio teórico com objetivo descritivo e análise, tornando-se então, necessário uma revisão dos temas estratégia, estratégia empresarial, vantagem competitiva e formas de competição para fundamentar a abrangência da GEC Gestão Estratégica de Custos, e o destaque dos custos relevantes como ferramenta de obtenção de vantagens econômicas e competitivas discutindo-se posteriormente a relação e integração destes conceitos. 


\section{ESTRATÉGICA E ESTRATÉGIA EMPRESARIAL}

Para WITTMANN, SOUZA, DUCLÓS, BENDLIN (2012), A definição de estratégia sempre foi voltada para área militar. Clássicos da literatura como a Arte da Guerra de San Tzu e O Príncipe de Maquiavel, abordam a questão da estratégia como um dos principais motivos do sucesso de líderes, seja no governo de uma nação ou mesmo em estratégias de vitórias em batalhas.

Os mesmos autores, afirmam que a mudança do foco da estratégia partindo do âmbito militar para o empresarial, ocorreu na década de 1950 quando foi apresentado o relatório Gordon-Howell (1959), na qual concluiu-se que a disciplina de política de negócios deveria ser uma das matérias chaves do curso de administração. Posteriormente, com a evolução da administração a disciplina mudou o foco e começou a ser chamada de administração estratégica.

Bacic (2008) descreve que a estratégia deve ser entendida em duas perspectivas complementares. A primeira perspectiva, que tem Porter o principal autor, destaca que a formulação da estratégia acontece em momentos onde não ocorrem grandes inovações e as estruturas empresárias estão estáveis. A segunda perspectiva, na qual Hamel e Prahalad são os autores mais conhecidos, parte do princípio que as inovações moldam o mercado e, alteram as estruturas empresariais. Segundo esse autor, a segunda perspectiva da estratégia acaba alterando significativamente o mercado e eleva a Gestão de Custos há um patamar superior na elaboração estratégia.

Para Bacic (2008), Bispo, Almeida e Souza (2011), uma nova estratégia irá demandar novos e os mais variados recursos para a empresa. Os autores destacam, que a nova estratégia acabará alterando a estrutura da empresa e consequentemente os custos.

Bispo, Almeida e Souza (2011) complementam que a definição da estratégia envolve escolha entre cursos alternativos de ação e impactam a estrutura organizacional, produtos e tipos de recursos.

\section{A GESTÃO ESTRATÉGICA DE CUSTOS E A RELEVÂNCIA}

A gestão estratégica de custos consiste no uso das informações de custos no processo de gestão empresarial. Para tanto, é preciso unir a estrutura de custos e a estratégia de negócio. Segundo Shank e Govindarajan (2008), a gestão estratégica de custos é entendida como uma análise de custos que considera elementos estratégicos com vistas a desenvolver estratégias de negócio, de modo a obter vantagem competitiva sustentável. Com a gestão estratégica de custos, as organizações 
desenvolvem meios de sustentar vantagens competitivas e, com isso, podem oferecer produtos e serviços diferenciado se melhores em relação aos seus concorrentes.

Porter (1999), afirma que a gestão estratégica de custos tem a finalidade de identificar tipos de gastos e direcioná-los, com base na cadeia de valor. Objetiva reduzir os custos ao máximo para tornar o produto/serviço cada vez mais competitivo sem que a lucratividade e qualidade sejam minimizadas.

Para Shank e Govindarajan (2008), a gestão estratégica possui três pilares, que são:

Análise da cadeia de valor, análise de posicionamento estratégico e análise de direcionamento de custos.

Por meio desses pilares, as empresas conseguem analisar as atividades em que há agregação de valor. Esse processo vai além da cadeia de valor global, pois envolve o negócio como um todo. Uma entidade não está isolada no ambiente, uma vez que existe um sistema de interação em cada ciclo de operação.

Shank e Govindarajan (1997) argumentam que os conceitos de análise de custos e Gestão Estratégica de Custos são diferentes. Para os autores, a visão mais clássica de Gestão de Custos tem como fundamento as análises financeiras das decisões tomadas pela direção. Por outro lado, a Gestão Estratégica de Custos, para os autores "É uma análise de custos vista sob um contexto mais amplo, em que os elementos estratégicos tornam-se mais conscientes, explícitos e formais”. (1997, p. 4).

A ampliação da visão de Gestão de Custos para a visão de Gestão Estratégica de Custos é observada também por Souza e Clemente (2007) e Bacic (2008). Nesse sentido, Martins (2003, p. 315) ressalta que a Gestão Estratégica de Custos vem sendo utilizada para “(...) a integração que deve haver entre o processo de gestão de custos e o processo de gestão da empresa como um todo”. A integração da Gestão de Custos com a gestão da empresa faz-se necessária, de acordo com Martins (2003, p. 515) para “(...) que as empresas possam sobreviver num ambiente de negócios crescente globalizado e competitivo”.

Para Shank e Govindarajan (1997) e Martins (2003), a visão mais ampla das análises de custos inter-relacionada com os elementos estratégicos fornece melhores informações para a administração. Shank e Govindarajan (1997), Souza e Clemente (2007) e Bacic (2008) ainda apontam o elo de ligação da Gestão Estratégica de Custos com a vantagem competitiva ao afirmarem que esta pode ser criada a partir de informações de custos que auxiliam na elaboração de estratégias. 


\section{VANTAGEM COMPETITIVA EM CUSTOS}

As empresas precisam lidar com a competição. Para Porter (2004), as empresas precisam encontrar um diferencial para se sobressair em relação aos concorrentes. $\mathrm{O}$ autor destaca que as empresas precisam criar uma estratégia e conseguir uma vantagem competitiva.

Para enfrentar as forças competitivas do mercado, Porter (2004) destaca que existem três estratégias genéricas para superar as demais empresas e criar vantagem competitiva:

(i) liderança no custo total; (ii) diferenciação; e (iii) enfoque.

A estratégia de liderança em custos consiste em ter o custo mais baixo possível do mercado. Para manter esta estratégia é necessário que a empresa tenha grande escala de produção para o rateio de custos e despesas fixas. Além disso, é preciso possuir uma grande parcela do mercado para absorver essa quantidade produzida. Por se tratar de grandes volumes de produção o poder de barganha dos fornecedores é reduzido.

Como o objetivo, da estratégia de liderança, é ter o menor custo do mercado, os preços praticados podem ser menores em comparação a concorrência ou até mesmo semelhantes, garantindo assim uma elevada margem de lucro. O lucro muitas vezes é investido novamente na própria empresa, por meio de equipamentos mais modernos ou melhorias de processo, tendo como o objetivo a manutenção do baixo custo (PORTER, 2009).

PORTER, M. (1980) com base nos conceitos apresentados nessa disciplina (I/O) introduziu no livro Estratégia Competitiva (1980) as técnicas para análises dos setores econômicos e competidores, apresentando cinco forças de mercado que impõem a necessidade de as empresas escolherem um posicionamento estratégico para competir, que consistem em: (1) Ameaça de novos entrantes, (2) Poder de barganha dos compradores, (3) Poder de barganha dos fornecedores, (4) Rivalidade entre competidores do setor, e (5) Produtos substitutos.

Juntamente com o conceito das cinco forças, PORTER (1980), introduz o conceito das estratégias competitivas genéricas, que consistem em: (1) Liderança em custos, (2) Diferenciação do negócio, e (3) Foco.

Em seguida, PORTER (1985) introduziu os conceitos das vantagens competitivas, no livro "Vantagem competitiva: criando e sustentando um desempenho superior", com as quais uma organização deve esperar ter um desempenho superior. 
Uma separação entre as abordagens analíticas da estratégia e vantagens competitivas pode ser identificada: (a) focada nas forças estruturais da Economia Setorial (ES), na qual focaliza-se nas forças estruturais dentro do setor empresarial, no ambiente competitivo das empresas e como esses influenciam a vantagem competitiva; e (b) focada na Visão Baseada nos Recursos (VBR), na qual tomam-se por base os recursos da empresa como mais importantes do que a estrutura setorial para a obtenção e manutenção da vantagem competitiva.

O conceito de vantagem competitiva pode ser expresso da seguinte maneira: "a capacidade única ou rara (de uma organização) para criar e distribuir, produtos ou prestar serviços valiosos aos olhos dos clientes".

O conceito de estratégia competitiva pode ser expresso como: "a busca por uma posição competitiva favorável em um setor ou linha de negócios".

Deve-se ter com clareza que: competitividade é uma característica dos agentes, enquanto que concorrência é uma característica dos mercados.

O conceito de competitividade pode ser expresso como: a capacidade de uma empresa crescer e sobreviver de modo sustentável.

A busca por capacidade competitiva teve por aliada a tecnologia da informação em que muitas empresas se apoiaram para obter uma diferenciação e também redução de custos, uma vez que a preferência do consumidor pelo produto é a mais forte vantagem competitiva, ter os custos interno e externo baixos representa a segunda e terceira vantagens competitivas mais poderosas.

Shank, J. \& Govindarajan, V. (1989) no livro "Strategic cost analysis: the evolution from managerial to strategic accounting", aponta que a análise de custos convencional deveria migrar para uma análise mais ampla, a fim de contemplar todo o ambiente externo que influenciava os custos das empresas, iniciando a busca por um sistema de Gestão Estratégica de Custos (SCM - Strategic Management Costing).

O que surpreende é o fato de que as análises devam começar na seleção das estratégias, o que ocorre bem antes de se ter registros contábeis para gerar informações contábeis, isto é, na garimpagem das questões certas.

Entre as empresas competitivas, não há duas exatamente iguais, e consequentemente que não há um modelo genérico único de solução para todas as circunstâncias e todas as empresas, isto é, cada uma deve buscar o seu próprio modelo.

Muitos fatores determinam essas diferenças, como: tempo de vida, estágio de evolução tecnológica, atratividade do setor, competência gerencial, estágio do ciclo 
de vida e assim por diante. Apenas um sistema de registros adequadamente formatado para representar a estratégia pode retratar as condições reais de competitividade da empresa e revelar aos executivos as informaçóes necessárias para avaliar suas condições para competir.

Nesse ambiente evolutivo, a questão da relevância dos custos deve conduzir a mapas de processos diferentes para cada arquitetura competitiva que a empresa adotar, significando que os custos relevantes para uma arquitetura, podem não ser os mesmos para empresas que adotam arquitetura diversa.

\section{ANÁLISE ESTRATÉGICA DE CUSTOS}

Os sistemas de informação adotam como modo de organizar os sistemas, arquiteturas justapostas, a fim de permitir o entendimento e o desenvolvimento da modelagem de sistemas e de estruturas organizacionais.

A base conceitual dos modelos, até há pouco existentes e novos, é revisada para encaixar-se na lógica da arquitetura organizacional, deforma a permitir a aprendizagem desses novos conceitos por gestores dos vários escalóes, treinados e acostumados ao raciocínio instrumental das teorias da economia de empresas neoclássicas, dentro do arcabouço no qual a empresa era vista como agente isolado, sem fazer parte de uma cadeia produtiva e cadeia de valores, competindo para derrotar os concorrentes, enquanto que na economia dos custos de transações, dentro do raciocínio instrumental da "Organização Industrial" - as empresas buscam a cooperação em forma de clusters (aglomerados) para melhor competirem.

Competir em clusters segundo PEREIRA, E. PEREIRA (2002) requer análises de custos que envolvam os parceiros do negócio a montante e a jusante na cadeia de valores, num posicionamento estratégico em que o alinhamento dos custos estruturais e de execução devem ser analisados de acordo com a estratégia do conjunto de parceiros, desde a extração do insumo mais básico, passando pela logística e processos de entrada, logística e processos de conversão, logística e processos de saída, até os processos de conversão de produtos perigosos em substâncias inócuas à saúde humana, bem como dos serviços ao cliente.

Em decorrência, maior importância tem sido atribuída aos modelos de Gestão Estratégica, sob a qual sistemas adequados com a modelagem adequada, tanto em termos conceituais quanto tecnológicos práticos, sejam factíveis, agora representado não mais pelo lucro contábil ou econômico do negócio, mas em função do alinhamento das estratégias, estruturas, capacidades diferenciadoras, fatores 
críticos de sucesso e vantagens competitivas sustentáveis, em busca do sucesso empresarial, cuja maturação dos investimentos podem experimentar retornos negativos inicialmente, mas altos retornos ao longo do ciclo de vida do negócio como um todo. Disso decorre que, na Administração, as teorias de Gestão Econômica fazem parte do raciocínio instrumental, desde a base de sustentação conceitual para decisões e controle.

\section{INFORMAÇÕES PARA A GESTÃO ESTRATÉGICA DE CUSTOS}

Segundo Pereira, E. Pereira (2002), o convívio com a incerteza requer apoio de equipamentos, "hardware e software", para conduzir os processos de análises e se obter otimizações probabilísticas com redução de riscos a níveis aceitáveis para determinadas circunstâncias, ou administrá-los por planos contingenciais.

Além da complexidade científica do tratamento do conhecimento exigido, o fator tempo e a dedicação para lidar com questões estratégicas requer muito de intuição (cérebro direito, imagético, sintético) dos gestores.

A percepção da granulometria dos fatores envolvidos e suas interações parecem depender mais da coragem de assumir riscos - por meio de alinhamentos estratégicos - do que de análises (cérebro esquerdo, fonético, analítico-lógico), que por vezes promovem a "paralisia por análises".

Um Sistema de Informação Executiva (SIE) assiste os executivos sêniores com os problemas não estruturados, focalizando as informações necessárias, combinando dados de fontes internas e externas, criando ambientes genéricos e comunicações que podem ser focalizadas e aplicadas a um arranjo de problemas em mutação.

A integração do SIE com outros sistemas permitem que a comunicação da visão, da missão e o processo de planejamento estratégico das organizações elejam as diretrizes estratégicas, definam cenários, definam objetivos parciais da organização, bem como objetivos das áreas de responsabilidade, projetos de investimentos e, consequentemente, os "custos devir" ou custos planejados que, ao entrar em operação, serão os custos operacionais, padrão e realizado com as informações disponíveis no Banco de Dados, o que torna fácil a apuração dos Indicadores Econômicos e Estratégicos.

De uma perspectiva estratégica, a alta administração estará preocupada em gerir a participação da organização no setor econômico em que está inserida, seus relacionamentos externos e, a longo prazo, com os clientes, fornecedores e concorrentes, numa cadeia de criação de valores permanentes. 
Entretanto, as informações que devem estar nos relatórios para a tomada de decisão devem refletir: (a) as perspectivas dos proprietários em termos de retorno sobre o capital empregado, (b) as perspectivas de satisfação dos clientes, (c) as perspectivas dos processos internos, e (c) as perspectivas de aprendizagem e crescimento, segundo orientação do Painel de Indicadores Estratégicos propostas por KAPLAN \& NORTON (1996).

A exigência de indicadores de resultados e de desempenho, propostas no Painel de Indicadores Estratégicos (Balanced Scorecard), combinando cifras financeiras com as não financeiras, envolvem os custos com a cadeia de suprimentos, os custos com a arquitetura adequada para a implementação da estratégia, os custos com a qualidade, os custos ambientais e outros assuntos relevantes. Os custos com a Cadeia de Suprimentos, na qual se obtém uma vantagem competitiva para assegurar a sobrevivência no longo prazo, devem ser a meta da gestão estratégica de custos.

Ainda segundo PEREIRA, E. PEREIRA (2002), estratégias diferentes criam conjuntos diferentes de atividades. Ao atribuir custos para atividades, os custos de estratégias diferentes podem ser avaliados. A combinação específica e ênfase relativa das estratégias definem a posição estratégica de uma empresa.

O objetivo da gestão estratégica de custos é reduzir os custos, enquanto simultaneamente se fortalece a posição estratégica de uma empresa. $\mathrm{O}$ conhecimento das atividades estruturais e de realização, e dos seus direcionadores de custos, é fundamental para a análise estratégica de custos.

O conhecimento da cadeia de valores da empresa e da cadeia de valores setorial também é crítico. Uma boa gestão de custos das ligações com fornecedores e clientes exige um entendimento do quanto acuradamente custam os fornecedores e o processo de atender os clientes. As atribuições de custos por atividade para fornecedores e clientes fornecem as informaçôes acuradas sobre custos que são necessárias.

A gestão do custo do ciclo de vida está relacionada à estratégia da empresa e é também fundamental para a análise estratégica de custos, exigindo um entendimento de três pontos de vista: (i) marketing; (ii) produção; e (iii) vida consumível do produto.

Os inter-relacionamentos entre os três pontos de vista fornecem discernimentos que ajudam os gestores a otimizar os resultados.

O custeio alvo tem um papel essencial na gestão do custo do ciclo de vida ao fornecer uma metodologia para a redução de custos no estágio de projeto, ao considerar e explorar as ligaçóes com o cliente e com o fornecedor. 
O suprimento e a manufatura sob a filosofia Just-In-Time (JIT) oferecem um conjunto muito diferente de atividades estruturais e de realização daquelas oferecidas na organização funcional tradicional. As diferenças entre as estruturas JIT e as estruturas organizacionais tradicionais podem ser usadas para ilustrar os tipos de atividades organizacionais e direcionadores de custos, que podem ser geridas para que uma vantagem competitiva possa ser criada e mantida. Os procedimentos JIT também têm um impacto sobre o sistema de gestão de custos ao mudar a rastreabilidade de custos, aumentando a precisão do custeio do produto e do processo, oferecendo um sistema de contabilidade de custos menos complexo.

O custo com a arquitetura competitiva envolve a decisão por uma das opções entre três abordagens possíveis de contabilidade por responsabilidade:

1) Contabilidade por responsabilidade baseada em função, que focaliza as unidades organizacionais como departamentos ou divisōes, usa medidas de resultados financeiros e padrôes estáticos, e se beneficia dos níveis de referência para avaliar o desempenho, enfatiza o status quo e a estabilidade organizacional.

2) A contabilidade por responsabilidade baseada em atividade por sua vez se concentra em processos, usa medidas de desempenho e de resultado, emprega padrões dinâmicos, enfatiza e apoia a melhoria contínua.

3) A contabilidade por responsabilidade baseada em atividade adiciona a perspectiva do processo às perspectivas da área de responsabilidade.

A contabilidade por responsabilidade baseada em estratégia expande o número de dimensões de responsabilidade adicionando as perspectivas do cliente e de aprendizagem e crescimento. As medidas de desempenho se tornam um conjunto integrado de medidas, identificadas à missão e a estratégia da organização.

A análise do valor do processo é o ponto central da contabilidade por responsabilidade por atividade. A análise do valor do processo fornece informações sobre por que o trabalho é feito, e quão bem este é feito. Envolve a análise dos direcionadores de custos, a análise da atividade, e a mensuração do desempenho. Um ponto chave do controle por atividade é a análise desta - o processo de identificação e descrição das atividades de uma empresa, mensurando o seu valor para a organização, e selecionando as atividades de valor. A redução de custos é obtida ao diminuir, eliminar, selecionar, e partilhar atividades. A ênfase é colocada na identificação de 
custos que não adicionam valor e eliminando-os, ou mensurando aquelas atividades que mesmo não adicionando valor são essenciais para a manutenção das vantagens competitivas.

Os relatórios de custos que adicionam valor, e que não adicionam valor, tendências nos custos, níveis de referência, e padrões de melhoria contínua são exemplos de medidas financeiras da eficiência da atividade.

Os orçamentos por atividade são o reverso do custeio por atividade. Começam ao identificar o volume e o composto de produtos e de clientes: depois avaliam as demandas que estes objetos de custos colocam nas atividades; e finalmente, estimam os recursos físicos, os custos dos recursos e a capacidade da atividade necessários para satisfazer as demandas para a produção da atividade.

Produzir orçamentos em nível da atividade permite que os gestores administrem melhor os custos e que façam ajustes para as mudanças na capacidade. Os orçamentos flexíveis da atividade possibilitam orçamentos precisos, porque reconhecem que o comportamento de custos é mais complexo do que as definições tradicionais, por função, de custos variáveis e fixos, análise custo-volume-lucro.

O Painel de Indicadores Estratégicos funciona como um sistema de gestão estratégico que traduz a visão e a estratégia de uma organização em objetivos e metas operacionais. Isto produz uma estratégia que pode ser testada e que fornece feedback estratégico para os gestores. O Painel de Indicadores Estratégicos torna-se compatível com a contabilidade por responsabilidade baseada em atividade porque focaliza os processos e requer o uso de informações por atividade para implementar muitos de seus objetivos e mensurações.

Os custos com a qualidade exigem o entendimento de que primeiro é necessário entendimento adequado do que é a qualidade. Há dois tipos de qualidade: a qualidade do projeto e a qualidade da conformidade. A qualidade do projeto se preocupa com as diferenças de qualidade que surgem para produtos com a mesma função, mas com especificações diferentes. Por outro lado, a qualidade da conformidade se preocupa em satisfazer as especificaçôes exigidas pelo produto.

Há também duas abordagens para a qualidade:

1) A abordagem de defeitos zero, que permite uma variação de um alvo dentro de certos limites das especificações.

2) A abordagem da qualidade robusta, que enfatiza a redução da variação, observando que qualquer variação acarreta custos ocultos de qualidade. 
Custos de qualidade são aqueles custos incorridos porque os produtos podem falhar ou realmente falham em satisfazer as especificações do projeto (e, portanto, estão associados com a qualidade da conformidade).

Há quatro categorias de custos da qualidade: (i) prevenção; (ii) avaliação; (iii) falhas internas; e (iv) falhas externas.

Os de prevenção são aqueles incorridos para prevenir a má qualidade. Os de avaliação são aqueles incorridos para detectar a má qualidade. Os de falhas internas são aqueles incorridos porque os produtos falham em estar em conformidade com os requisitos, e esta falta de conformidade é descoberta antes de uma venda externa. Os de falhas externas são aqueles incorridos porque os produtos falham em estar em conformidade com os requisitos após uma venda externa ser efetuada.

Um relatório de custos deve revelar os quatro tipos de custos com a qualidade. Em geral há dois pontos de vista com relação a atribuição ótima dos custos da qualidade, o ponto de vista convencional mantém que existe uma substituição entre os custos de falhas e os custos de prevenção e avaliação. Esta substituição produz um nível ótimo de desempenho denominado "nível aceitável de qualidade (Allowable Quality Level-AQL)”. O AQL é o nível no qual o número de defeitos aceitáveis minimiza o total dos custos da qualidade. Por outro lado, o ponto de vista da manufatura de classe mundial adota o controle da qualidade total (TQC). Este último mantém que o conflito entre os custos de falhas e os custos de prevenção e de avaliação é mais conjectura do que real. O nível ótimo de defeitos seria o nível de defeitos zero. Embora os custos da qualidade não desapareçam neste nível, eles devem ser muito mais baixos do que o ótimo previsto pelo ponto de vista convencional.

As informações sobre a qualidade são muito importantes para a estratégia, talvez a mais importante seja de que essas informações são fundamentais na busca por melhorias contínuas de uma empresa.

Os custos com a produtividade demonstram o quão eficiente e eficazmente os recursos são consumidos para produzir o produto. Medidas parciais da produtividade avaliam o uso eficiente de entradas únicas. Medidas totais da produtividade avaliam a eficiência de todas as entradas. Essencialmente, o efeito no resultado é computado ao analisar a diferença entre o custo dos recursos que teriam sido consumidos sem nenhuma mudança na produtividade e o custo dos recursos realmente consumidos. Por causa da possibilidade de substituições de recursos, é essencial avaliar as mudanças na produtividade. 
Somente desta forma é que o efeito das mudanças na produtividade pode ser corretamente julgado. Há duas abordagens que podem ser usadas para avaliar a eficiência da atividade: análise da produtividade da atividade e análise da produtividade do processo. A análise da produtividade da atividade é usada principalmente para avaliar mudanças na eficiência das atividades que adicionam valor. A análise da produtividade do processo pode ser usada para avaliar a produtividade de processos e de atividades que adicionam valor e que não adicionam valor, mas que definem o processo.

Os custos da gestão ambiental envolvem o entendimento de que os custos cada vez mais altos de conformidade e o surgimento da disciplina denominada ecoeficiência intensificaram o interesse no custeio ambiental. A ecoeficiência sugere que reduções de custos podem ser realizadas ao melhorar o desempenho ambiental.

Além disso, para muitas empresas os custos ambientais são uma porcentagem significativa dos custos totais de operação. Este fato, junto com a ecoeficiência, enfatiza a importância em definir, medir, e relatar os custos ambientais. Os custos ambientais são aqueles incorridos por causa da existência de má qualidade ambiental, ou porque esta má qualidade ambiental pode existir. Há quatro categorias de custos ambientais: (i) prevenção, (ii) detecção; (iii) falhas internas; e (iv) falhas externas.

A categoria de falhas externas é dividida em custos realizados e não realizados.

Os custos realizados são os externos que a empresa precisa pagar, e os custos não realizados, ou sociais, são aqueles causados pela empresa, mas que são pagos pela sociedade. $\mathrm{O}$ relato de custos ambientais por categoria revela a sua importância e mostra a oportunidade para reduzir os custos ambientais ao melhorar o desempenho ambiental.

Os gestores precisam decidir se atribuirão apenas os custos privados, ou se todos os custos sejam atribuídos (custo total). Depois, precisam decidir usar uma abordagem por função ou uma abordagem por atividade. Por meio do custeio por função um grupo de custos ambientais é criado e uma taxa é calculada usando direcionadores em nível unitário como as horas de mão-de-obra direta ou as horas-máquina.

Os custos ambientais são então atribuídos a cada produto, baseado no seu consumo de horas de mão-de-obra direta ou horas-máquina. Esta abordagem é provavelmente satisfatória para empresas com pouca diversidade de produto. 
Para empresas com grande diversidade de produtos as atribuições por atividade devem ser superiores. $\mathrm{O}$ custeio por atividade atribui os custos às atividades ambientai se depois calcula os índices das atividades. Estes índices são então usados para atribuir-se os custos ambientais aos produtos.

A avaliação do custo do ciclo da vida atribui custos para os impactos ambientais de projetos concorrentes de produtos. Estes custos são uma função dos materiais usados, da energia consumida, e das emissões de poluentes para o meio ambiente que resultam da manufatura de um produto. Assim, antes de avaliar as atribuições de custos, é necessário analisar o inventário que detalha os materiais, a energia e as emissões ambientais. Esta análise é executada ao longo do ciclo de vida do produto em si. Uma vez completada, os impactos financeiros e operacionais podem ser avaliados, e medidas tomadas para melhorar o desempenho ambiental.

O controle dos custos ambientais depende de um sistema de contabilidade ambiental por responsabilidade baseado em estratégia. Este usa duas características importantes: uma estratégica e uma operacional. A estratégica usa a estrutura do Painel de Indicadores Estratégicos. A adaptação para o controle ambiental é a adição de uma quinta perspectiva: a perspectiva ambiental.

A perspectiva ambiental possui cinco objetivos principais relativos a: (i) consumo de materiais; (ii) de energia; (ii) a produção; (iv) a emissão de poluentes ambientais; e (v) a reciclagem.

Algumas medidas para materiais reciclados são desenvolvidas para cada objetivo. A gestão baseada em atividade fornece o sistema operacional que produz melhorias ambientais. Atividades ambientais que não adicionam valor e as suas causas raízes são então identificadas. Melhorias eco-eficientes devem produzir efeitos financeiros favoráveis que podem ser medidos por meio de tendências nos custos ambientais totais.

\section{CONSIDERAÇÕES FINAIS}

De forma sintética, a Gestão Estratégica de Custos pode ser conceituada como uma análise das informações de custos dentro de um contexto mais amplo, isto é, além do foco no controle de custos ao longo de toda a cadeia de valor, com vistas a resultados, deve também subsidiar a análise, a princípio, da estrutura de custos que se instala com a estratégia concebida como também fazer a gestão das informações de custos relevantes à manutenção dessa vantagem competitiva. 
A organização elabora a estratégia e tem como o objetivo a criação de vantagem competitiva, que por sua vez pode ser temporária, uma vez que a concorrência irá atuar para tentar eliminar ou reduzir essa vantagem. A Gestão estratégica de custos se caracteriza, fornecendo informações sobre a nova estrutura de custos, resultante da estratégia escolhida, em um momento anterior ao investimento. Ao se optar pela escolha da estratégia empresarial, sobre a ótica da estrutura que se instalará, de fato haverá a gestão estratégica de custos. O controle operacional de gastos e despesas não necessariamente se caracteriza como gestão estratégica de custos. A Gestão estratégica de custos pode vir a ser um norteador importante na escolha da estratégia empresarial, uma vez que ela fornecerá informações importantes para a organização e principalmente na análise da estrutura de custos.

A importância da gestão estratégica de custos no âmbito da estratégia empresarial se torna evidente em um novo investimento, uma vez que essa ótica resultante da gestão estratégica de custos demonstra o resultado da operação futura.

Os resultados apontam que a gestão estratégica de custos na busca da vantagem competitiva, ocorre em duas fases. A primeira quando se faz a gestão da estrutura de custos que se instala com a estratégia que foi selecionada. A segunda quando as informações de custos subsidiam as decisões para a manutenção ou melhoria da vantagem competitiva já conquistada. Verificou-se então que no pressuposto inicial que a estratégia e a gestão estratégica de custos estão diretamente ligadas, obtendo vantagens econômicas e a gestão estratégica de custos pode servir como um norteador para a tomada de decisão. Contudo, caberá a organização e principalmente aos tomadores de decisão se a gestão estratégica de custos será levada em consideração na hora das decisões, pois o que não é relevante agora pode sê-lo num futuro próximo.

\section{REFERÊNCIAS}

ANSOFF, H. I. Estratégia Empresarial. São Paulo: McGraw Hill, 1977.

BACIC, M. J. Gestão de Custos: uma abordagem sob o enfoque do processo competitivo e da estratégia empresarial. Curitiba: Juruá Editora, 2008.

BISPO, C. M.; ALMEIDA, L. B. de; SOUZA, A. Artefatos de Custos e estratégia: um ensaio buscando a demarcação do conceito de Gestão Estratégica de Custos. In: XII Congresso Internacional de Costos, 2011. Punta Del Este. XII Congresso Internacional de Costos, v. 1. 2011.

CHANDLER Jr., A D. Strategy and Structure: Chapters in the History of the Industrial Enterprise, Cambridge, MIT Press, 1962. 
COOPER, R. \& KAPLAN, R. S. The Design of Cost Management Systems: Text, Cases, and Readings, 1st edition [The Rise of Activity Based Costing - Part One, p. 355, Part Two, p. 366], Englewood Cliffs, Prentice hall, 1991.

DRUCKER, P. F. The Practice of Management, New York, Harper \& Row, 1954. , Managing for Results, London: Pan Books, 1967.

JOHNSON, H. T. \& KAPLAN, R. S. Contabilidade Gerencial (Relevance Lost), Rio de Janeiro: Campus, 1993.

JOHNSON, H. T. Relevância Recuperada, São Paulo, Pioneira, 1994.

KAPLAN, R. S. \& NORTON, D. P. Organização Orientada para a Estratégia, Rio de Janeiro: Campus, 2001.

KAPLAN, R. S.; ANDERSON, S. R. The innovation of time-driven activity-based costing. Cost Management, v. 21, n. 2, p. 5-15, mar./abr. 2007.

MARTINS, E. Contabilidade de custos. 9. ed. São Paulo: Atlas, 2008.

MILLER, J. G. \& VOLLMANN, T. E., The Hidden Factory, HBR, set-out/1985, p. 142-150.

MINTZBERG, H. \& QUINN, J. B. O Processo da Estratégia, 3. ed., Porto Alegre: Bookman, 2001.

PEREIRA, E. A Contabilidade e o Capital Intelectual, Goiânia, XVI Congresso Brasileiro de Contabilidade - CFC, 18/10/2000.

PEREIRA, E. PEREIRA, I. S. E. A gestão Estratégicas de custos e os custos relevantes. In: Anais do Congresso Brasileiro de Custos-ABC. 2002.

PORTER, M. E. Competição, Rio de Janeiro, Campus, 1999.

. Estratégia Competitiva, Rio de Janeiro, Campus, 1991.

. Vantagem Competitiva, Rio de Janeiro, Campus, 1992.

- Estratégia Competitiva: técnicas para análise de indústrias e da concorrência.

2. ed. Rio de Janeiro: Elsevier, 2004.

. Competição - Edição Revista e Ampliada. São Paulo: Campus, 2009.

REDDIN, W. Administração por Objetivos: o método 3-D. São Paulo, Atlas, 1978.

. The Output Oriented Organization, Hampshire, Gower Publishing, 1988 (versão traduzida para o português por Editorial Presença, 1989).

RITTA, C.O. CITTADIN, A. PEREIRA, B.S. Análise da produção científica sobre a gestão estratégica de custos no Congresso Brasileiro de Custos. Revista de Estudos Contábeis, Londrina, v. 6, n. 10, p. 76-95, 2015.

SAMUELSON, P. A. \& NORDHAUS, W. D. Economia. 12. ed. Lisboa, McGraw-Hill, 1988. 
SHANK, J. \& GOVINDARAJAN, V. Gestão Estratégica de Custos, Rio de Janeiro, Campus, 1997.

SHANK, J.; GOVINDARAJAN, V. A revolução dos custos: como reinventar e redefinir sua estratégia de custos para vencerem mercados crescentemente competitivos. 4. ed. Rio de Janeiro: Campus, 2008.

SOUZA, A.; CLEMENTE, A. Gestão de Custos: aplicações operacionais e estratégicas: exercícios resolvidos e propostos com utilização do Excel. São Paulo: Atlas, 2007.

WITTMANN, G. SOUZA, A. DUCLÓS, L.C. BENDLIN, L. Caracterizando a gestão estratégica de custos na busca de vantagem competitiva, XIX Congresso Brasileiro de Custos - Bento Gonçalves, RS, Brasil, 12 a 14 de novembro de 2012.

ZACCARELLI, S. B. Estratégia e Sucesso nas Empresas, São Paulo, Saraiva, 2000. 
